\title{
Examining Public Social Responsibility (PSR) through digital responsibility
}

\author{
Dr. habil. Balázs Benjámin BUDAl, PhD. \\ Mátyás GÁSPÁR
}

\begin{abstract}
The megatrends of the digital age, changes in competitive culture, and the dimensions of sustainable development have redefined the concept of social value and its interrelated duties, including the identity of the parties that are responsible for undertaking such actions. These trend spirals bring to the forefront the unavoidability of individual and community actions; supporting - and in some cases, coordinating these actions - is the duty of the state/ local government. Social integration has been noted in a diverse selection of documents for quite a long time; digital inequality (and consequently the digital catchup effort) - one of the most significant segregation inducing factors - has only become a defining factor in the current "third generation" strategies. Our paper presents the most significant stages for catching up, potential points where actors can intervene, and pinpoints the responsibility for undertaking this effort. Finally, we define specific tasks that can be integrated into the routine of public administration under the label of an administrative Public Service Responsibility task.
\end{abstract}

\section{Keywords}

Public Social Responsibility, Corporate Social Responsibility, digital safety, digital competencies, digitalization.

\section{Introduction}

Debate is ongoing about public responsibility, since the accountability of state and public administrative bodies that serve the public good and the public interest moves within considerably narrower confines than formerly. ${ }^{1}$ The focal point of this line of inquiry is digital responsibility, where - alongside many other factors - the locations where catch-up efforts are being undertaken in the digital arena can be identified for the various actors, including the question of what the content should be, whose responsibility it is to protect users and digital space, and to have trust in it all.

1 R., GARDE-SANCHEZ, M. Victoria LÓPEZ-PEREZ, A. M. LÓPEZ-HERNÁNDEZ: Current Trends in Research on Social Responsibility in State-Owned Enterprises: A Review of the Literature from 2000 to 2017; Sustainability 2018, 10, 2403; https://doi.org/10.3390/su10072403. 
Nowadays, the digital age and the world wide web create megatrends that overturn the decades or centuries long reflexes, routines, and customary operational principles of our societies. The robust changes to our information habits, the applied forms of communications, the tools we use for the same, these have an immediate impact on us. These changes, and the presence or lack of adaptive intelligence concerning the changes recreates those social and economic differences that induce segregation within society. To be blunt, those who lag behind are simply excluded. The naked truth, however, is that when one is unable to properly profit from the accelerated stream of information, he/she cannot access the most important resource of information society, is excluded from the information economy and its value chains. In the knowledge market, the less information demanding jobs require less qualified labor, those who receive less compensation. Consequently, they are less and less able to adopt changes in infocommunications tools and software or acquire required user know-how. Thus, the poor become even poorer (we can interpret this phenomenon on an individual, community, organizational and national level alike). Thus, as far as change is concerned, segregation results in lack of change. Relating to and regulating these trends on an individual, community, national and supranational level foreshadows serious responsibilities on each level.

Therefore, one of the most essential public administrative issues of the day is the role of social public responsibility within the digital ecosystem - with particular emphasis on the concept of digital inclusion - in the reflection of megatrends, on the level of various social classes. The examination of the digital catch-up effort in the light of megatrends is particularly important, because ignoring and not responding to innovation-based phenomena, services and customs results in segregation.

One of the most fundamental issues of competitive culture is the issue of the sort of field the companies are competing with one another on. The greatest challenge of the $21 \mathrm{st}$ century is that the significance of economic, environmental and social sustainability rose to an identical level, with an exceptional rise in the relative weight of the latter two. Thus, the latter have brought new dimensions of the economic competition to the surface, which is best captured through the concept of so-called social and/or shared value creation. ${ }^{2}$

This results in the expansion of the content of competitive culture, which means that in the economic and social judgment of the existence and purity of competition it has become more and more significant to induce a conscious awareness of the social value creation role of products and services, including all related capabilities and their presentation in the purview of private and public goods alike. The legal foundations of this process have begun to take shape. ${ }^{3}$

The business sphere has gradually recognized - in many stages, currently we are in generation 4.0 of Corporate Service Responsiblities - that CSR only translates into a competitive advantage for the affected companies when its content refers to sustainable development in a narrow sense, and societal value creation in a broader sense. In other

2 M. E. PORTER: Shared Value and Strategy; Shared Value Leadership Summit, New York, NY, May 12th, 2015; https://www.hbs.edu/faculty/Publication\%20Files/Michael\%20Porter\%20-\%20CSV\%20and\%20Strategy \%20presentation_5c6accd5-94ac-444c-ac01-24772ce95bfa.pdf (Accessed : 02/01/2021) and Benefits of Social Value http://www.socialvalueuk.org/what-is-social-value/the-benefits-of-social-value/ (Accessed: 02/01/2021).

3 R. CLAASEN and A. GERBRANDY: Rethinking European Competition Law: From a Consumer Welfare to a Capability Approach, Utrecht Law Review, Volume 12, Issue 1 (January) 2016; http://doi.org/10.18352/ ulr.321. 
cases, CSR unavoidably becomes hostage to other, peripheral struggles of society or local communities, and does not contribute to an increase in competitive ability. ${ }^{4}$

The most crucial issue in the context of corporate competition and the new dimensions of competitive culture is how - by whom and in what manner - it gets defined, and what societal value consists of, in general and with specificity, e.g., in a given time and space. This is where Public Social Responsibility (PSR) comes into play, meaning the social responsibility of the public sector, a crucial issue that defines the wellbeing of communities, nations and the globe alike.

Where is the boundary of public responsibility for enforcing the public good/public interest? The term "public duty" could be an explanatory synonym of public responsibility, which provides a direct answer to the question by its very expression. In this regard, the respected authority we can cite is none other than the OECD SIGMA/PUMA Shared Principles of Public Administration among EU Member States, which "classifies the generally enforced principles in the legal systems of the member states, according to the following groupings: 1.) reliability and calculability, 2.) openness and transparency, 3.) accountability (public responsibility), 4.) efficiency and effectiveness". ${ }^{5}$ Thus, the content and boundary of public responsibility is accountability for activities performed in the service of the public good and public interest, as mandated by law.

Consequently, public responsibility arises by a legal mandate e. The range of motion of public administration (more broadly defined as the organizations of the public sector) exists by its very nature, due to function, in some cases, as a result of discretionary action deriving from general legal authorization, and freedom to effect solutions and operate the organization, that is beyond mere service or enforcement for the public interest/public good. Until proven otherwise, we can risk making the assertion that this can be shown in the case of every public institution. In case of local governments (for French model municipalities), it is in the nature of general authorization to undertake duties on a voluntary basis. This class includes activities undertaken in harmony with the respective missions, authorizations of public sphere organizations, within the framework of procurements, agreements, partner agreements, and other expressions of intent (e.g. planning, organization, coordination) that is not based on direct legal obligation.

It is proven that public institutions and service providers continuously perform activities that serve the public good and public interest beyond the level of public responsibility, with such activity undertaken on the basis of various reasons without making it obvious that this is none other than operating in what is well defined in the business sector as Corporate Social Responsibility, or CSR. When the public agency strives to handle cases faster in a more efficient manner, with more accessibility, (or strives to avoid having to address, intervene, impose action or punish in the matter of the case at all) by offering client training, information services, advertising, community outreach or online services, it can somewhat exceed its legally expressed, narrowly interpreted enforcement/executive role.

4 M. REEVES, D. HEUSKEL, T. LEWIS: Social Advantage, https://www.bcg.com/publications/2010/businessunit-strategy-social-advantage.aspx (Accessed: 02/01/2021).

5 TORMA A.: Az Európai Közigazgatási Térségröl - magyar szemmel (About the European Administrative Area from a Hungarian perspective,), Miskolci Jogi Szemle, 6. évfolyam, 2011, különszám, http://www.mjsz.uni-miskolc. hu/201102/15_tormaandras.pdf (Accessed: 02/01/2021). 
An obvious and tangible international trend in the business sector has been the intersectoral, hierarchical, thematic expansion of the standardization and globalization of social responsibility (the four together: Global/Collective Social Responsibility, GSR). In this process, governments are the most significant economic actors and define their own roles as catalyzers of the civil sector. The issue of the public sector's own social responsibility, however, has only arisen in recent years, as a separate function exceeding far beyond that of CSR promotion, and applicable to the entire public sector.

The following trends reinforce the above ideas:

CSR TREND 1 - The initial recognition of Corporate Social Responsibility was that business can only be sustained in the long term if it does not cause social, economic and environmental (TBL - Triple Bottom Line or People, Planet, Profit (3P).) damage. Today's perception is that only those businesses are competitive which can contribute to solving problems and development goals in these three themes. The shift from risk management to strategic development has become an obvious trend. ${ }^{6}$

CSR TREND 2 - The direct consequence of the previous trend is that CSR, as in the case of PR (Public Relations), is shifted from the point of chance altruism to the Social Responsibility Sub-Strategy in the company's comprehensive future planning system. This aim and trend is epitomized by classics such as Michael Porter and Mark Kramer, who propose the transformation of the value chain in which the organization's internal and external social value-creation activities are also displayed. ${ }^{7}$ Such companies are called B-Corporations, ${ }^{8}$ which build a more sustainable and inclusive economy.

CSR TREND 3 - It is evident that an international trend is altering from fully volunteered social responsibility towards a partial mandatory operating condition through various stages (see the legal elements of PSR in greater detail below). Such stages (which have induced greater debates): certain PSR elements becoming mandatory, voluntary alignment to state expectations or requirements, the benefit of adapters, and soft law solutions such as ISO 26000 or SA 8000 CSR.

GSR TREND - Social Responsibility becomes intersectoral and global, as organizations from different sectors and individual citizens are increasingly seeking each other in solving the problems of society and utilizing opportunities. Corporate, public, civil and personal (individual) responsibility is globalized into a multifaceted collaboration, "Global / Collective Social Responsibility". However, the question arises whether the process remains spontaneous, or should this collaboration be coordinated. The trend shows the latter (see below). ${ }^{9,10}$

6 E. ABAD-SEGURA, F. J. CORTÉS-GARCÍA, L. J. BELMONTE-UREÑA: The Sustainable Approach to Corporate Social Responsibility: A Global Analysis and Future Trends. Sustainability 2019, 11, 5382; https://doi.org/10.3390/ su11195382.

7 M. E. PORTER - M. R. KRAMER: Creating Shared Value. Harvard Business Review, 2011. 01-02., 2-17.

8 https://bcorporation.net/about-b-lab (Accessed: 02/01/2021).

9 Y. TANG, Y. MA, C.W.Y. WONG, X. MIAO: Evolution of Government Policies on Guiding Corporate Social Responsibility in China. Sustainability 2018, 10, 741; https://doi.org/10.3390/su10030741.

10 L. ALBAREDA, J. M. LOZANO, A. TENCATI, A. MIDTTUN, Francesco PERRINI: The changing role of governments in corporate social responsibility: drivers and responses. Business Ethics: A European Review Volume 17. Number 4. (2008). 
PSR TREND - As it is proven by the KÖFOP ${ }^{11}$ study, internationally as well as in Hungary, public sector organizations have been mostly latently undertaking "beyond mandatory" social responsibility activities. However, there is an increasing awareness of the trend that the public interest activity is not automatically socially responsible. This finding is not easy to see immediately, because public good and public interest make public responsibility self-explanatory. But the latter - which essentially "only" means accountability, does not include social responsibility as well. That is why it is necessary to interpret and cultivate Public Social Responsibility, as an administrative function at individual levels and public institutions.

ISR TREND - The essence of personal, Individual Social Responsibility is represented by voluntary movements, respectively, any other personal or family activity that we make in the spirit of the responsibility for each other, for the community and for society. ${ }^{12}$ Personal solidarity is not at all a new phenomenon. As a trend it can be grasped: settlement, regional, national institutionalization, globalization, integration into the economy and society as a specific "task-solving organizational system", which in this form can become part of the GSR's personal level, partly through the well-known civil society system. An important element of this change, besides many others, ${ }^{13}$ is the gradual transformation of episodic volunteering into life-course volunteering.

IT/DTTREND - The unmistakable, perceived, simultaneously destructive and constructive effects of Digital Transformation, often referred to as the 4th Industrial Revolution, labeled for the most vital issue, namely, IT/DT. What is the social value of the process? The World Economic Forum gave the answer. ${ }^{14}$ Since digital transformation affects almost all aspects of our lives, the examination of its presence and impact in the process of producing social value needs to be given special attention, in particular to address barriers to social inclusion and reduce existing inequalities. ${ }^{15,16,17}$

OD TREND - An additional and more general trend, not completely independent of the above trends, proves that through collaboration, organizations will be more successful in all sectors. It is increasingly evident that the organizations and management that are based on the masses, atomization, division of labor and hierarchy that have emerged from

11 KÖFOP - Közigazgatás Fejlesztési Operatív Program - Public Administration Development Operational Program.

12 A. DEVALIA: PSR v CSR: Is personal social responsibility still good for business? https://www.mycustomer. com/selling/sales-performance/psr-v-csr-is-personal-social-responsibility-still-good-for-business

(Accessed: 02/01/2021).

13 C. ROCHESTER: Trends in Volunteering. http://volunteernow.aw-stage.co.uk/app/uploads/2018/10/Trendsin-Volunteering-Final-Report.pdf (Accessed: 02/01/2021).

14 Unlocking Digital Value to Society: A new framework for growth - White Paper, World Economic Forum, 2017. http://reports.weforum.org/digital-transformation/wp-content/blogs.dir/94/mp/files/pages/files/dti-unlockingdigital-value-to-society-white-paper.pdf (Accessed: 02/01/2021).

15 M. COOK, T.M. HARRISON: Using public value thinking for government IT planning and decision making: A case study; Information Polity, 20 (2/3) (2015), 183-197.

16 W. BAl: A Public Value Based Framework for Evaluating the Performance of e-Government in China; iBusiness, Vol. 5 No. 3B, 2013, 26-29. doi: http://doi.org/10.4236/ib.2013.53B006.

17 BANNISTER, F., CONNOLLY, R.: ICT, public values and transformative government: A framework and programme for research; Government Information Quarterly 31, 1, January 2014, 119-128. 
the industrial revolutions so far and which are generic in the economy, the state in operation and in society cannot be sustained in the future. The sharp boundaries between sectors, organizations, and management levels are blurred by a growing holistic approach. In all three sectors, the growing importance of collaboration, hybrid organizations and community solutions are becoming more and more widely recognized.

PS TREND - Nowhere in the world has the provision of public services (PSs) exclusively belonged in a specific sector, individual or family of sectors. Transitions and overlaps are constant between social actors. The trend witnessed in the developed world is the increasing strength of cooperation, shared and corporate solutions, and complementary support for each other in the pursuit of the common social goals, e.g. MDG (Millennium Development Goals). ${ }^{18}$ This raises the increasing importance of the sectoral coordination mechanisms with the responsibility of public administration, such as the English Public Service (Social Value) Act (2012) and its extended practice. ${ }^{19}$

Materials and Methods

Within the framework of highlighted project number KÖFOP-2.1.2-VEKOP-15-2016-00001, titled "Public Service Development as a Foundation of Sound Governance, Social Public Responsibility - Social Responsibility in the Public Sphere, the Role of Public Administration in the Effective Operation of Intersector Partnerships," the Ludovika Research Group has participated for over a year in broad research and professional cooperative efforts at the National University of Public Service. The goal of the research was the exploration of the Hungarian situation, contrasting it with international trends, and express the directions and opportunities of moving forward.

One of the most spectacular fields of PSR functions is the entirety of digitalization, digital transformation, and the development of the digital ecosystem, for even though these contribute significantly to the development of society, they do come with numerous negative externalities. Thus, while on the one hand we are deploying tools for the development of the digital world, in parallel and automatically with this effort, greater and greater tasks arise on the other hand that mitigate naturally arising anomalies.

Our research focused on the clarification of three issues in this field:

1. How the inclusion related PSR relate in the digital field to the strategies (Here we examined what areas these strategies did or did not address). This line of questioning created the foundation of the regulatory environment as well.

2. What it means, what is the ever expanding content of relevant digital competencies? Where are the scenes of digital catchup for given actors? Where do we see best practices?

3. Whose responsibility is the protection of users and user trust, of the digital space? What is the content of such protection?

First, we examined the interpreted role of social public responsibility in the digital ecosystem - highlighting the concept of digital inclusion - as reflected in megatrends, on each societal level. The study of digital catchup in light of megatrends is important, as ignoring

18 D. ELFFERS: CSR and Government role in SDGs, http://www.emg-csr.com/csr-and-government-role/ (Accessed: 02/01/2021).

19 M. TALIENTO, C. FAVINO, A. NETTI: Impact of Environmental, Social, and Governance Information on Economic Performance: Evidence of a Corporate 'Sustainability Advantage' from Europe. Sustainability 2019, 11, 1738; https://doi.org/10.3390/su11061738. 
or non-responding to phenomena, services and habits that are built on innovation results in segregation. Relating to trends on an individual, community, national and supranational level and regulating the same outlines a serious responsibility on the various levels.

After sketching out the theory, we have examined the international digital inclusive strategic efforts. Side by side, we saw first generation catchup programs - mainly programs seeking to eliminate disparities in access - and third generation programs - seeking to reduce quality usage disparities; the proportions reflect the level of development of the given nations, however. At the same time, tools are used from each of the three groups of tools to improve inclusion.

\section{Results}

\section{Strategic documents}

Ever since the symptoms of information society, strengthened with infocommunication tools, have been showing an ever more intensive presence in Europe, the decisionmakers of European countries have been feeling the need to respond to these challenges with strategies, action plans, and programs. These responses are not merely of symbolic significance; they are truly determinative in a competitiveness context: the quantitative and qualitative indicators of access to infocommunication tools and services fundamentally define the competitiveness of an individual, community, organization or nation.

The development of digital skills is included in nearly every larger strategic document. Added to this is the support of information dissemination activities over the course of 10 - 12 years, and the heightening of the catchup status of those who are on different levels of development (inclusivity, if necessary, even by enabling the catching up of disadvantaged population segments). E-learning and telecommuting often appear as peculiar categories of information society.

The strategies reflect an unusual shift in tone here:

- First generation catchup programs target the elimination of the access divide (between those with and those without access). Their tools are: Infocommunication technologies provided to individuals, the establishment of public internet access points (PIAP), providing broadband network access, etc.

- Second generation programs target the user divide (between users and non-users). Their tools: enabling access for those with special needs (eAccessibility), the development of digital literacy, the expansion of services - content development (primarily in the fields of public services and e-public administration).

- Finally, third generation programs attempt to steer the divide reflecting the quality of service (what the users use it for) in a substantive direction. Their tools are campaigns improving trust and knowledge, initiation of niche market services (reaching narrow target groups), initiatives improving civil discourse and inclusion

As long as we are discussing three generations, we can observe each of these three generations in Hungary (and in other, less developed countries). While improving inclusivity, tools are utilized from each of the three tool groups. 
Even though social strategies for information have been placing lesser and greater emphasis on transforming the members of the population into digital citizens since 1993, following initial enthusiasm, this reality has only come to pass in the years around the turn of the millennia. Around this time, alongside content development, the elimination of informational social anomalies has become more and more of a focal point, thus the implementation of the Safer Internet Action Plan, and to enable the catching up of disadvantaged countries, social classes, and groups. Even now, this latter initiative remains significant under the name "Inclusion Europe." In subsequent strategies, inclusion was emphatically emphasized in eEurope programs (eEurope 2002 - action plan [COM (2000) 330 final] - 2000 and eEurope 2005 [COM (2002) 263 final] - 2002) via digital accessibility and simplifying network access (reducing prices, mitigating taxes, improving infrastructure, enabling access to software developed for people with disabilities, advancing digital literacy, etc.).

Of the three iSociety priorities of the program for European Information Society for growth and employment (i2010 strategy), the third - inclusion - concerns the creation of a European information society. Social, economic, and geographic cohesion is sought to be achieved by providing high quality public services and improving quality of life. In the interest of this objective, it recommended equal opportunity programs, programs aiding the catch-up effort in information communications technology skills, and programs mitigating regional digital divides.

This was continued by the $i 2010$ eGovernment Action Plan, which had listed among its goals to be achieved by 2010 the speeding up of social integration through the improvement of the level of preparedness of human resources. Of its five priorities, it has designated the elimination of (digital) obstacles before the online accessibility of public services, an element of the struggle against the digital divide. The eAccessibility and elnclusion programs had strengthened these objectives.

In the Malmö ministerial declaration issued in November 2009, inclusion is once again an area of emphasis, as this tool can improve not just competitiveness, but also expand the circle of participants of public services; involving participants in the development of public services can yield additional returns. Inclusion is expanded to the utilization of digital services as well, as the utilization of social subsidies or e-health services also implements inclusion in a physical sense. They had also assigned specific target values to the improvement of the activity level and willingness to utilize user feedback: They expected the implementation of the action plan to accomplish the following with regard to the following:

By 2015, at least 50 percent of EU citizens and 80 percent of its enterprises should be an active e-government user. An important component of this declaration is that (in part as a result of the worldwide financial crisis), under the label of a public administration duty, it recommends the undertaking of informational activities to citizens, for the utilization of financial services, for instance (an important PSR task milestone).

The e-government action plan following the Malmö declaration recommends the empowerment and preparation of users under the aegis of inclusion; to enable them to proactively make use of the services to be offered by the state, to inspire, formulate and continuously review the work of the government. 
The Europe 2020 growth strategy considers digital skill development to be a special tool for the improvement of competitiveness and employment. This area affects two of the three thematic tools:

- Value creation through knowledge transfer. ${ }^{20}$

- Increasing opportunities for people in accepting societies.

Of its highlighted initiatives, the European Digital Timeline emphasizes the development of digital know-how and digital skills, encouraging the involvement of as many people as possible in the digital world. The timeline of New Skills and Jobs designates our field The Digital Timeline has also expressed 16 key measures, of which two of them directly assist the case of improving the cause of digital know-how, digital skills, and digital inclusion.

- It mandates that the decree on the new European Social Fund (2014-2020) should emphatically deal with digital know-how and digital competencies. They wished to accomplish this goal through the more intensive coordination of member state level initiatives associated with the development of IT skills, and by making digital know-how and digital competency into an ESA priority.

- It mandates the development of tools - in connection with the European certification framework and Europass - to identify competencies that are necessary for ICT professionals and users, urging an acknowledgment of such necessity Furthermore, it recommends the establishment of the European framework of the ICT profession in the interest of expanding the competencies of ICT professionals and improving their mobility within Europe.

The most recent strategic document was the Tallin declaration on e-governance, ${ }^{21}$ adopted during the Estonian EU presidency, which - among others - expects accepting and accessible digital solutions from the member states.

These strategies signal that the EU has, from the very beginning, assigned the digital catchup effort into the national sphere, but supports it with large-scale subsidy programs. Since the appearance of information society strategies (with varying degrees of emphasis and depth of content), this has been signaling that failure to undertake these tasks has a segregational effect: if the inclusion programs do not take place, classes that are left behind are excluded from society. Thus, their economic potential and quality of life also go down. The task of the prevailing government is therefore the continuous improvement of the necessary catch-up infrastructure in the field of know-how as well, and to develop services that help speed up (and support) the catch-up effort, and to bring them closer to the user. Thus, the EU has been marking the path for a quarter of century and schedules necessary steps, launching programs in order to support national efforts. At the same time, it appears that the advancement of technology in the future justifies the catch-up effort as well, giving rise to tasks for each and every societal actor.

\section{Digital competencies - digital (catch-up) sites}

20 A. CORDELLA, C.M. BONINA: A public value perspective for ICT enabled public sector reforms: A theoretical reflection; Government Information Quarterly, 29 (4) (2012).

21 https://www.interregeurope.eu/erudite/news/news-article/1769/tallinn-declaration-on-egovernment/ (Accessed: 02/01/2021). 
The content of the catch-up effort consists of the development and perfection of digital competencies throughout society, nearly in its entirety. Part of this can be undertaken through institutions (can and should be within school walls), however, most of it is taking shape as a PSR (Public Social Responsibility) task. It appears that it is necessary to develop digital competencies, to strategically plan, supplement, or augment the system of conditions for lifelong learning (perfecting the ability to adapt), here and beyond public education.

Having recognized the foregoing, there have been more and more targeted and centrally coordinated catch-up programs (educational and continuous education), that assist those who lag behind in a local (family, close to the home) environment, using local (or locally integrated) mentors, so that those lagging behind can get closer to digital services via a complex perspective affecting every dimension of the lag, by improving competencies. With regard to effectiveness, those small community or inter family programs where a member of the small community or family with information technology skills (or with more experience) performs the catch-up activity, eliminating the differences in knowledge. Community catch-up efforts are most easily imagined when we base them on PIAPs (Public Internet Access Points). There, digital services can be presented, thus openness towards the digital world can be established for less advantaged citizens not possessing digital competence. At these same points, trainings, continuous education and motivational courses (built on top of one another), targeting digital competence, can be implemented for this segment of the population.

The prevention of attrition becomes important from the community level onward as a preventive activity - which is strategically at least as important as the development of digital competencies. The catch-up responsibility of individual societal actors (duty of cooperation) is self-evident. From the perspective of our subject matter, civil organizations are primarily important due to their signaling function. As they are able to signal every social need, it is self-evident for other social actors as well that they should seek cooperation with civil actors, since they can point out problems to be solved. The responsibility of helping the competitive sector's catch-up efforts can be witnessed at the moment of their inclusion in the digital ecosystem. This inclusion can take numerous forms, but the most obvious solution is the cooperation of the competitive sphere and education in the interest of strengthening digital competencies.

The crucial terrain of the catch-up effort is the arena where accessibility is ensured within public administration. It is an essential condition of the spread of comprehensive userfriendly, speedy and comfortable services that in order to bridge the potential obstacles to access of clients - due to physical and digital inequality - public administration must take appropriate measures. At first glance, digital accessibility efforts to deal with electronic access means the support of the disadvantaged that arise from digital inequality. This phenomenon, also referenced as so-called e-acceptance targeted at the disadvantaged, typically includes measures with the goal of expanding advantages arising from the use of ICTs.

As the final area of study, we highlight the tasks of creating and preserving public trust and safety, the responsibility of danger and risk avoidance. It is an essential condition of the spread of infocommunication services and the expansion of the universe of users, that the users be cognizant of the security of their devices and data, self-utilizing the services 
with full confidence. The tasks that are outlined here - in a PSR context - are primarily informational in nature, the users must be able to distinguish between factual and assumed (fictional pseudo elements) phenomena, while contrary to the former, they must be aware of the self-evident variations of avoidance and defense.

\section{The duty of ensuring accessibility}

Assuming that the state supports (or at least does not prohibit or is allowing space for it) the increased adoption of infocommunications technologies, then its resulting responsibility is the mitigation of associated anomalies, including their elimination. The new media has become an agent of socialization, which forces children and older generations (who were not born into a technology-based environment) alike into the role of students. Not to mention that the territory of this new media has expanded past the internet to mobile devices as well, as the services integrated into the devices can already compete with any home PC. Users unskilled in virtual space - independent of age - can be victimized with childhood naivete by every anomaly (the age issue only plays a role in the degree to which the user can be influenced). We see six areas where social public responsibility must (also) be exercised:

1. Protection of young users from damaging and illegal content,

2. The protection of young users from ill-intentioned persons (e-pedophília, cyberbullying)

3. The protection of users from untrue content and transactions (the protection of the reliability and credibility of virtual space),

4. The defense of the identity, virtual agency and assets of users (cybercrimes)

5. The protection of users from psychological distortions (information clutter, information anxiety, internet dependence, functional neurological disorders)

6. Keeping digital culture properly aligned, defending against the degradation of communications.

The duty to catch-up affects every actor, via the active role played by public administration or through its assistance.

Any advanced user on the family or small community level (e.g. a worker at a local governmental office) can take on a mentoring role and provide assistance (by teaching and learning at the same time) in practicing and perfecting digital competence-based activities. In this circle, it is particularly worthwhile to analyze solutions developed for especially (or cumulatively) disadvantaged persons, the expansion of lifelong learning opportunities, strengthening the potential acceptance of a digital future. Thus, the PSR tasks of digital solidarity begin with the signaling of catch-up opportunities (connecting educational materials, teaching spaces, instructors and target audiences) and the mentoring and tutoring process, and conclude with the support of opportunities inherent in connectivity, in the support of participation and access, and in ensuring access. In individual and family catch-up efforts, the mission is for the users of the future to:

- Get to know the fundamental nature of online communications;

- In spite of the nature of the digital medium, be able to establish healthy social-emotional bonds; 
- Be able to use digital (fixed and mobile) technologies in a disciplined (within limits) manner. To be able to connect and relax alike;

- Develop cognitive critical thinking as it pertains to online information, content and actors;

- Proactively protect themselves from risks arising in the online space;

- Develop a strong identity as a responsible digital citizen;

- Get to know as broad (substantie) service portfolio as possible and solve problems in the virtual space in a confident manner.

Just as it is nearly everywhere in the public administration realm, there are best practices here already, reflecting or forming the foundation of PSR activities. Of these, we have explored many dozens in Hungary and internatinonally alike.

The civil actors perform a control function, since they strengthen pluralism by often highlighting alternative opportunities, opinions, potential solutions that are contrary to the position of the government, often also providing an alternative model to undertake this effort (this is why their operation can be often jeopardized, as these activities can often cease as a consequence of these activities). Self-financing tools are limited: they are either performing business activities as well, or they sustain themselves from membership fees or charitable contributions. Additionally, members can also assist the mission of the organization via voluntary participation, although this is often insufficient to sustain the framework). The significance of civil actors is strengthened by digitalization and the technologies that are based on it. These solutions more easily provide opportunities for the reclaiming of operations of public matters and services (crowdsourcing) as well.

From the point of view of our topic, however, civil organizations are primarily important due to their signaling role. As they are capable of signaling every social need, then it is selfevident to all societal actors to seek cooperation with civil actors, as they point out problems that require a solution. The primary motif of cooperation (the importance of which has also been pointed out by McKinsey Consulting) is the restoration of trust through the integration of consumer feedback and expectations. The government and the competitive sphere alike often diverge from real social problems. Digital technologies provide an opportunity to monitor government and business activities and to transmit comprehensive societal error signals. In other words, nowadays civil actors are experiencing an intensive expansion of the system of tools of civil control (and when the opportunity arises, make use of them), over and above state and corporate social responsibility. ${ }^{22}$

Responsibility for the competitive sector's catch-up efforts is witnessed at the moment of its inclusion within the digital ecosystem. This inclusion can take several forms, but the most obvious solution is the cooperation of the competitive sector and education for the purpose of strengthening digital competencies. The development of human resources is of crucial importance for the competitive sector, as they are the ones who receive the labor that is produced by the educational system. Well trained labor suited to market expectations powers the competitiveness of companies. Dual and adult trainings provide an opportunity for the competitive sector to develop targeted trainings, while at the same time, participating in joint $\mathrm{R}+\mathrm{D}+\mathrm{I}$ programs enables the same on the university level (through the establishment

22 J. BROWNE and R. NUTTALL: Beyond corporate social responsibility: Integrated external engagement, https://www.mckinsey.com/business-functions/strategy-and-corporate-finance/our-insights/beyond-corporatesocial-responsibility-integrated-external-engagement (Accessed: 02/01/2021). 
of research workshops, competency centers, incubation houses, etc.). The application of $\mathrm{R}+\mathrm{D}+\mathrm{I}$ activity connected to innovative infocommunications technologies is the other defining factor of competitiveness. The incentivization and support of international cooperation to be implemented in this field visibly improves the effectiveness of innovation. Its ripple effects expand to other sectors and to the consumption habits of clients as well (and to the habits that enable the same). Incentivization appears to be most effective (beyond the above referenced forms) in cluster development (e.g.: the establishment and support of clusters and the training of cluster experts).

Additionally, a potential opportunity arises on both the user and service provider side of the digital economy, assuming that services supporting connection (e.g.: electronic corporate governance, electronic communications, electronic settlements, e-billing, e-payments, etc.) enjoy priority in business life. It is the responsibility of the competitive sector to determine how fast it switches over to digital solutions, to what degree it forces competitors and partners to operate in this medium.

PSR may consist exclusively of the coordination and support of, and in consulting for, these activities.

An important area of the catch-up effort is ensuring digital accessibility in public administration. It is an essential condition of the comprehensive spread of user-friendly, fast and convenient services that public administration take appropriate steps to bridge potential obstacles of clients that arise from physical and digital inequality. On the initial approach, ensuring digital accessibility means the support of those who are disadvantaged due to digital inequality. This phenomenon, also known as e-acceptance, includes measures with the goal of expanding advantages derived from the use of ICT.

In other words, the support of access of those, who do not have access to infocommucation devices is considered - among others - a form of ensuring accessibility. Once access to devices is ensured, ensuring access to service for those with some kind of a disability follows. The integration of people with disabilities, sensitivity training for their inclusion, and the performance of activities that go beyond obligations mandated by law can arise in the form of PSR activities.

Every smart city development has an important indirect and impetus forward, as it is these developments through which achieved improvements in quality of life extend to every member of the settlement (or every resident), irrespective of their digital literacy, illiteracy, or disability. Similarly, non-digital literate persons also receive benefit, even if they receive specialized administrative (e.g.: child welfare, child protection, social, etc.) services. ${ }^{23}$ Indirectly, the creation of all digital services represents further impetus forward, as they can be interpreted as an important argument before potential users, in the interest of acquiring know-how.

Finally, it is also worth mentioning the issue of public trust and safety. It is an essential condition for the spread of infocommunication services and the expansion of the the user pool that the users believe that their devices and data are secure and that they can trust the services. The PSR related tasks outlined here are mainly informative in nature: The users must be able to distinguish between real and fictional phenomena (false pseudo

23 Nemzeti Infokommunikációs Stratégia (National Infocommunication Strategy) 2014-2020, https://www. kormany.hu/download/a/f7/30000/NIS_v\%C3\%A9gleges.pdf (Accessed: 02/01/2021). 
elements), while regarding the former, we must become cognizant of the obvious versions of avoidance and defense.

\section{Discussion and Conclusion}

Public social responsibility activity can be properly captured within the public sector; it can be delineated and defined, and its criteria described with appropriate precision. They are obviously present on every level and area of the public sector however, this presence is rarely conscious and coordinated (of course, we do see several organizations that have consciously interpreted their PSR operations and expressed its associated core values, strategy, partnership network, and methodically organizes its functions in this field, performing a series of successful programs, and reporting of such activities).

We have identified the strengthening process of harmonization among social responsibility sectors as an international trend, including the implementation of its cross-border collectivization and globalization (Collective/Global Social Responsibility). As a result of the research, we have detected the international trend that the enforcement of social responsibility within the dimension of voluntary undertakings and legal obligations is a mandate of soft law, and has moved gradually, through alternate means, in an incentivizing manner, but unequivocally in this direction.

Operations and activities that have been identified under the PSR label are implemented at a proportionately higher rate on the local government level, mainly due to the fat that their general legal authorization for undertaking volunteer duties can essentially be classified into this category (Consequently, the digital catch-up effort and digital responsibility must be strongest on the local level).

One of the most outstanding results of PSR is the so-called social value regulations, which demand results and contributions that are interpreted in given fields and increasing specific economic, social and environmental well-being from nearly every activity conducted in the public sector (public services, procurements, investments, cooperation, subsidies). ${ }^{24}$ In social public responsibility, social catch-up efforts constitute an area of emphasis; its content is the development and perfection of digital competencies nearly throughout the entirety of society. Part of this effort can be institutionalized (can and should be constrained within school walls), but a larger proportion of it has been outlined as a PSR function. A need appears to arise for the development of digital competencies, for the strategic planning, augmentation or supplementing of the system of conditions (support environment) of lifelong learning (the perfection of adaptive abilities), over and beyond the boundaries of public education; specifically:

- The development of the continuously updated catalogue of minimally necessary digital competencies, based on societal consensus;

- The recruitment, training, and continuous education of volunteer trainers;

- The development of cooperation among actors and the development of a significant level of volunteer activity (sensitization);

- The perfection of the level of dedication of target groups;

24 M. SCOTT, W. DELONE, W. GOLDEN: Measuring eGovernment success: A public value approach; European Journal of Information Systems, 25 (3) (2016) 187-208. 
- The publication of use-oriented, open education content;

- And methodological recommendations appear essential (on community and national level alike).

For the protection of users, pursuant to domestic and international regulations, the following - uniformly applicable - tools are on offer:

- Operation of hotlines.

- Informational guidance, education (the learning process is the crucial aspect: the recognition of what is actually useful and what is useless for the individual. In this process, the recognition of what is bad, as well as its alternative must be presented as well, so that the child can act appropriately due to the insight gained, and not just due to the absence of a better alternative. This learning process must be take aim at not just the target audience, but also at those segments, where the child is undergoing socialization (e.g.: parents, teachers. This line of inquiry raises the issue of the need for PSR in this area.)

- Filtering - labeling - the limitation of accessible content. Filtering can be implemented on an individual, institutional, service provider, or state level (state level filtering can also be implemented through service providers, when the service provider blocks sites on the basis of a list, or it can also be implemented by installing the filter on the country's incoming telecommunications backbone, which blocks the regulation violating content for all domestic IP addresses.)

- The voluntary or involuntary removal of web sites or making the content transferring IP addresses inaccessible.

- Supporting self-regulation/co-regulation and the generation of codes of conduct.

We have already seen numerous, well-functioning examples of these tools. ${ }^{25} \mathrm{It}$ is now our shared responsibility to answer the question of whether we are successful in magically transforming the system of philosophy of PSR into a law of operation, contributing to the sustainable development of society.

\section{Funding}

This research was funded by the European Union and the Hungarian Government. Project number KÖFOP-2.1.2-VEKOP-15-2016-00001, titled "Public Service Development as a Foundation of Sound Governance, Social Public Responsibility - Social Responsibility in the Public Sphere, the Role of Public Administration in the Effective Operation of Intersectoral Partnerships. KÖFOP (PADOP) funded a number of researches in Hungary. During this program, a PSR Research Group was established, which has produced several significant studies on this topic.

25 L. TETREVOVA, M. JELINKOVA: Municipal Social Responsibility of Statutory Cities in the Czech Republic. Sustainability 2019, 11, 2308; https://doi.org/10.3390/su11082308. 


\section{References}

ABAD-SEGURA, E. - CORTÉS-GARCÍA, Francisco, J. - BELMONTE-UREÑA, Luis, J.: The Sustainable Approach to Corporate Social Responsibility: A Global Analysis and Future Trends. Sustainability 2019, 11, 5382. Available from: https://doi.org/10.3390/su11195382.

ALBAREDA, Lozano - LOZANO, Josep, M. - TENCATI, Antonio - MIDTTUN, Atle -PERRINI, Francesco: The changing role of governments in corporate social responsibility: drivers and responses. Business Ethics: A European Review, 17, 2008, 4.

BAI, Wenlin: A Public Value Based Framework for Evaluating the Performance of e-Government in China; iBusiness, 5, 2013, 3b, 26-29. Available from: http://doi. org/10.4236/ib.2013.53B006.

BANNISTER, Frank-CONNOLLY, Regina: ICT, public values and transformative government: A framework and programme for research; Government Information Quarterly, 31, 2014, 1, 119-128.

Benefits of Social Value http://www.socialvalueuk.org/what-is-social-value/the-benefits-ofsocial-value/ (Accessed: 02/01/2021).

BROWNE, John - NUTTALL, Robin: Beyond corporate social responsibility: Integrated external engagement, https://www.mckinsey.com/business-functions/strategy-andcorporate-finance/our-insights/beyond-corporate-social-responsibility-integratedexternal-engagement (Accessed: 02/01/2021).

CLAASEN, Rutger - GERBRANDY, Anna: Rethinking European Competition Law: From a Consumer Welfare to a Capability Approach, Utrecht Law Review, 12, January 2016, 1. Available from: http://doi.org/10.18352/ulr.321.

COOK, Meghan - HARRISON, Teresa, M: Using public value thinking for government IT planning and decision making: A case study; Information Polity, 20 (2/3) (2015), 183-197.

CORDELLA, Antonio - BONINA, Carla, M.: A public value perspective for ICT enabled public sector reforms: A theoretical reflection; Government Information Quarterly, 29, $2012,4$.

DEVALIA, Arvind: PSR v CSR: Is personal social responsibility still good for business? Available from: https://www.mycustomer.com/selling/sales-performance/psr-v-csr-ispersonal-social-responsibility-still-good-for-business (Accessed: 02/01/2021).

ELFFERS, Daan: CSR and Government role in SDGs Available from: http://www.emg-csr. com/csr-and-government-role/ (Accessed: 02/01/2021). 
GARDE-SANCHEZ, Raquel - LÓPEZ-PEREZ, Victoria, M. - LÓPEZ-HERNÁNDEZ, Antonio, M.: Current Trends in Research on Social Responsibility in State-Owned Enterprises: A Review of the Literature from 2000 to 2017; Sustainability 2018, 10, 2403; Available from: https://doi.org/10.3390/su10072403

https://bcorporation.net/about-b-lab (Accessed: 02/01/2021).

Nemzeti Infokommunikációs Stratégia (National Infocommunication Strategy) 2014-2020, Available from: https://www.kormany.hu/download/a/f7/30000/NIS_v\%C3\%A9gleges.pdf (Accessed: 02/01/2021).

PORTER, Michael, E. - KRAMER, Mark, R.: Creating Shared Value. Harvard Business Review, 2011, 01-02, 2-17.

PORTER, Michael, E.: Shared Value and Strategy; Shared Value Leadership Summit, New York, NY, May 12th, 2015; Available from: https://www.hbs.edu/faculty/Publication\%20 Files/Michael\%20Porter\%20-\%20CSV\%20and\%20Strategy\%20presentation_5c6accd594ac-444c-ac01-24772ce95bfa.pdf (Accessed : 02/01/2021).

REEVES, Martin - HEUSKEL, Dieter - LEWIS, Thomas: Social Advantage. Available from: https://www.bcg.com/publications/2010/business-unit-strategy-social-advantage.aspx (Accessed: 02/01/2021).

ROCHESTER, Colin: Trends in Volunteering. Available from: http://volunteernow.awstage.co.uk/app/uploads/2018/10/Trends-in-Volunteering-Final-Report.pdf (Accessed: 02/01/2021).

SCOTT, Murray - DELONE, William - GOLDEN, Willie: Measuring eGovernment success: A public value approach; European Journal of Information Systems, 25, 2016, 3, 187-208.

TALIENTO, Marco - FAVINO, Christian - NETTI, Antonio: Impact of Environmental, Social, and Governance Information on Economic Performance: Evidence of a Corporate 'Sustainability Advantage' from Europe. Sustainability, 2019, 11, 1738. Available from: https://doi.org/10.3390/su11061738.

TANG, Yanhong - MA, Yanling - WONG, Christina, W., Y. - MIAO, Xin: Evolution of Government Policies on Guiding Corporate Social Responsibility in China. Sustainability, 2018, 10, 741. Available from: https://doi.org/10.3390/su10030741.

TETREVOVA, Libena - JELINKOVA, Martina: Municipal Social Responsibility of Statutory Cities in the Czech Republic. Sustainability, 2019, 11, 2308. Available from: https://doi. org/10.3390/su11082308. 
TORMA András: Az Európai Közigazgatási Térségröl - magyar szemmel (About the European Administrative Area - from a Hungarian perspective,), Miskolci Jogi Szemle, 6. évfolyam, 2011, különszám. Available from: http://www.mjsz.uni-miskolc.hu/201102/15_ tormaandras.pdf (Accessed: 02/01/2021).

Unlocking Digital Value to Society: A new framework for growth - White Paper, World Economic Forum, 2017. Available from: http://reports.weforum.org/digital-transformation/ wp-content/blogs.dir/94/mp/files/pages/files/dti-unlocking-digital-value-to-society-whitepaper.pdf (Accessed: 02/01/2021).

\section{Author}

Dr. habil. Balázs Benjámin Budai, PhD.

Department Chair, Associate Professor, Lead Researcher

Nemzeti Közszolgálati Egyetem Államtudományi és Nemzetközi Tanulmányok Kar National University of Public Service

Faculty of Political Sciences and International Studies

Üllói út 82, 1083 Budapest, Hungary

budai.balazs@uni-nke.hu

Mátyás Gáspár

Lead Researcher, Honorary Associate Professor

National University of Public Service

Faculty of Political Sciences and International Studies

Department of Public Management and Infotechnology

Üllói út 82, 1083 Budapest, Hungary

gaspar.matyas@uni-nke.hu 